\title{
CULTIVO DE PLEUROTUS SAJOR-CAJU EM DIFERENTES SUBSTRATOS PASTEURIZADOS
}

\section{E. Bernardi'; J.S. Nascimento ${ }^{2}$}

${ }^{1}$ Universidade Federal de Pelotas, Instituto de Biologia, Departamento de Microbiologia e Parasitologia, Laboratório de Micologia, CP354, CEP96010-900,Pelotas, RS, Brasil.E-mail: bernardieduardo@yahoo.com.br

\section{RESUMO}

Este trabalho objetivou avaliar a viabilidade do cultivo de Pleurotus sajor-caju utilizando diversos resíduos gerados na região de Pelotas, RS. Os substratos foram formulados com bagaço de cana-de-açúcar, capim-elefante e palha de arroz, utilizando-os separados e misturados entre si, totalizando sete tratamentos. Os substratos foram umedecidos por 24 horas, pasteurizados a $100^{\circ} \mathrm{C}$ durante 30 minutos, sendo em seguida adicionado de 3\% de "spawn" de P. sajor-caju (PSC96/03) e acondicionado em embalagens de polietileno de $1 \mathrm{~kg}$. A incubação foi a 25-28 C, durante 25 dias e a colheita ocorreu em dois fluxos durante 45 dias cada. Os cogumelos foram coletados e pesados para a avaliação da massa fresca $(\mathrm{g})$, produtividade (\%) e eficiência biológica (\%). Os resultados mostraram que a palha de arroz produz mais no primeiro fluxo e o capim-elefante no segundo, porém, no somatório dos dois fluxos para massa fresca e produtividade, destaca-se o cultivo de P. sajor-caju no capim-elefante e a eficiência biológica na palha de arroz, sendo ambos, separadamente, substratos viáveis para o cultivo de cogumelos. O bagaço de cana-de-açúcar foi o substrato menos indicado para o cultivo deste cogumelo por esta técnica.

PALAVRAS-CHAVE: Produtividade, eficiência biológica, cogumelos comestíveis.

\section{ABSTRACT}

CULTIVATIONOF PLEUROTUS SAJOR-CAJUIN DIFFERENTPASTEURIZEDSUBSTRATES. This research was aimed at evaluating the viability of the Pleurotus sajor-caju crop using various residues generated in the region of Pelotas, state of Rio Grand do Sul, Brazil. The substrates were formulated with sugarcane bagasse, elephant grass and rice straw, separate and mixed, for a total of 7 treatments. The substrates were moistened for 24 hours, pasteurized at $100^{\circ} \mathrm{C}$ for 30 minutes, and then seeded with a 3\% spawn of P. sajor-caju (PSC96/03) and placed into $1 \mathrm{~kg}$ polyethylene bags. The incubation was carried out at $25-28^{\circ} \mathrm{C}$, for 25 days, and the harvest took place in two flushes after periods of 45 days each. The mushrooms were collected and weighed for the evaluation of the fresh mass (g), productivity (\%) and biological efficiency (\%). The results showed that the rice straw produces more in the first flush and the elephant grass more in the second, while the overall totals for fresh mass and productivity of both flushes showed that each of these materials was, separately, a viable substrate for the cultivation of $P$. sajor-caju mushrooms. The sugarcane bagasse proved to be the least indicated substrate for the cultivation of this mushroom by means of this technique.

KEY WORDS: Productivity, biological efficiency, edible mushrooms.

\section{INTRODUÇÃO}

A demanda e a qualidade dos alimentos têm sido motivos de várias pesquisas, nas mais diversas áreas. Uma delas tem sido o desenvolvimento de técnicas para o cultivo de cogumelos, que visa à redução dos custos de produção, redução do preço e aumento do consumo mundial.

O gênero Pleurotus pertence à ordem Agaricales e à família Agaricaceae, sendo amplamente distribuído mundialmente. As espécies de Pleurotus apresentam uma grande variedadede cores como branco, marrom, azul claro e rosa que variam de acordo com a espécie, assim como a incidência de luz durante a frutificação, necessidades nutricionaise tempo deincubação. Neste gênero são encontradas muitas espécies comestíveis como Pleurotus ostreatus, P. pulmonarius, P. sajor-caju, P. oeus, entre outros (EIRA; MinHONI, 1997).

A produção de cogumelos comestíveis em substratos naturais envolve etapas de laboratório,

${ }^{2}$ Universidade Federal da Paraíba, Centro de Ciências da Saúde, Departamento de Fisiologia e Patologia, João Pessoa, PB, Brasil. 
relativas à obtenção de linhagens e produção do inoculante, relacionadas com as etapas de cultivo que vai desde a inoculação até o beneficiamento (EIRA; MinHONI, 1997; MARINO, 1997).

EIRA; MinHONI (1997) descreveram uma série de resíduos agrícolas e agroindustriais que podem ser reciclados no cultivo de cogumelos comestíveis como: bagaço de cana-de-açúcar, palha de soja, palha de aveia, sabugo de milho, palha de trigo, palha de arroz, gramíneas, serragens, polpa e casca de frutas, folhas de bananeira, diversos tipos de forragens, dentre outras. Por estes materiais serem rejeitos da agroindústria, a reciclagem deles torna-se ecológica e economicamente viável.

Pleurotus produz uma série de enzimas lignocelulases, que permite degradar facilmente a lignina e a celulose da madeira, assim como outros substratos vegetais utilizados para o seu cultivo. É um dos agentes causadores da podridão branca da madeira, porém, não atua como parasita de árvores, mas como saprófito que se desenvolve sobre madeira morta (CAPELARI, 1996).

Os fungos secretam enzima durante seu desenvolvimento degradando compostos para obtenção de carbono, nitrogênio, enxofre e outros nutrientes necessários para seu crescimento. O bagaço de canade-açúcar é um substrato pobre nutricionalmente, com maior teor de celulose que os demais, sendo que a celulose provê glicose para o fungo e, quando cessa esta fonte de açúcar, o fungo para de crescer, necessitando de açúcares facilmente metabolizáveis provenientes de polissacarídeos do substrato. No caso do cultivo de shiitake, o bagaço de cana-deaçúcar precisa ser suplementado e, quando isso acontece, é passível de ser utilizado para a produção de cogumelos comestíveis (RegINA, 2001).

SiLva et al. (2002) cultivaram P. pulmonarius em substratos contendo resíduos da cultura de algodão, folhas de capim Panicum maximum e em folhas do capim Cymbopogon citratus. Os cogumelos cultivados usando estes substratos apresentaram composição química variada, sendo que aqueles cultivados em resíduo de algodão mostraram alto valor de proteína e fibras. BERMUdÉz et al. (2001) cultivaram P. ostreatus var. Florida em substratos agrícolas como casca de cacau, polpa de café e casca de coco e obtiveram maior eficiência biológica quando cultivados em polpa de café, seguidos da casca de coco e casca de cacau. Como exemplificado acima, a pesquisa sobre o aproveitamento de resíduos agroindustriais deve ser realizada para cada situação, no intuito de selecionar aqueles que respondam a uma maior produtividade de cogumelos.

Oobjetivo deste trabalho foi avaliar a massa fresca, produtividade e eficiência biológica de $P$. sajor-caju cultivado em substratos palha de arroz, capimelefante e bagaço de cana-de-açúcar pasteurizados.

\section{MATERIAIS E MÉTODOS}

O experimento foi desenvolvido no Laboratório Experimental de Micologia (LEMICO), do Departamento de Microbiologia e Parasitologia (DEMP) do Instituto de Biologia (IB), da Universidade Federal de Pelotas (UFPel), RS.

Neste trabalho foi utilizada a espécie $P$. sajor-caju (linhagem PSC96/03) originada do Módulo deCogumelosFCA/UNESP/Botucatu/SP, sendodepositada na micoteca do LEMICO/DEMP/IB/UFPel.

A linhagem foi multiplicada em meio de cultura à base de capim-elefante + dextrose + ágar (Doninı et al., 2005) e incubada a $28^{\circ} \mathrm{C}$ por 7 dias, para obtenção de crescimento miceliano adequado.

Para o preparo do "spawn" ('spawn') foram utilizados grãos de sorgo (Sorghum bicolor L. Moench), previamente cozidos por 15 minutos, adicionados de $1 \%$ de gesso agrícola (v/v). Em seguida, foram acondicionados em frascos de vidro de 8,6 x14 cm, os quais foram fechados com papel alumínio e filme plástico e autoclavados a $121^{\circ} \mathrm{C}(1 \mathrm{~atm})$ por 45 minutos.

Após o processo de esterilização, os frascos foram inoculados com discos de $10 \mathrm{~mm}$ de diâmetro de cultura de cada linhagem, sendo em seguida incubados a $28^{\circ} \mathrm{C}$ até a colonização dos grãos pelo fungo, constituindo-se, assim, o "spawn".

Como substratos foram utilizados bagaço de cana-de-açúcar (Saccharum officinarum), palha de arroz (Oryza sativa) e capim-elefante (P. purpureum) secos, moídos ou picados.

Para o preparo do material a ser utilizado no experimento, os substratos foram previamente umedecidos por 24 horas, sendo posteriormente acondicionados em sacos de polipropileno de alta densidade e submetidos ao tratamento térmico a $100^{\circ} \mathrm{C}$ por 30 minutos.

Após resfriamento dos substratos, a temperatura de $30^{\circ} \mathrm{C}$, eles foram inoculados com $3 \%$ de "spawn" de P. sajor-caju (linhagem PSC96/03). Para isto, os substratos foram homogeneizados com o "spawn" em bandejas de plástico e acondicionados em sacos plásticos contendo $1 \mathrm{~kg}$ de substrato úmido cada. Os tratamentos foram constituídos de capim-elefante (100\%), bagaço de cana-de-açúcar (100\%), palha de arroz (100\%), capim-elefante (50\%) + cana-de-açúcar (50\%), capim-elefante (50\%) + palha de arroz (50\%), bagaço de cana-de-açúcar $(50 \%)+$ palha de arroz (50\%) e capim-elefante $(33 \%)+$ bagaço de cana-deaçúcar $(33 \%)+$ palha de arroz $(33 \%)$.

Os sacos foram dispostos em prateleiras à temperatura ambiente $\left(25-28^{\circ} \mathrm{C}\right)$ durante a fase de colonização. Após a completa colonização, os sacos foram transferidos para uma câmara de frutificação com temperaturas entre $23-28^{\circ} \mathrm{C}$ e umidade relativa do ar de $75-90 \%$. 
Os cogumelos foram coletados manualmentee as variáveis avaliadas foram massa fresca, produtividade em base úmida e eficiência biológica calculados conforme BERNARDI et al. (2007).

A análise de carbono e nitrogênio total do substrato foirealizada no Departamento deSolos/FAEM/ UFPel de acordo com o método Walkey-Black para carbono orgânico e Semimicro-Kjeldahl para nitrogênio (TEDEsco et al., 1995).

Os cogumelos foram caracterizados com relação a sua composição centesimal, em base seca: proteína bruta, cinzas, extrato etéreo, fibra bruta, carboidratos e umidade de acordo com as Normas Analíticas do Instituto Adolfo Lutz (1985), sendo estas análises realizadas junto ao Departamento de Zootecnia/ FAEM/UFPel.

Os resultados obtidos foram submetidos à análise da variação e ao teste de Tukey para comparação das médias, utilizando-se o programa estatístico SANEST (ZONTA; MACHADO, 1984).

\section{RESULTADOS E DISCUSSÃO}

Para massa fresca, produtividade e eficiência biológica a palha de arroz apresentou os melhores resultados no primeiro fluxo de produção. Já no segundo fluxo de produção o capim-elefante foi o substrato que desenvolveu os melhores resultados. Após os 90 dias de cultivo, o substrato capim-elefante apresentou as maiores médias 232,40 e 23,24 para massa fresca (g) e produtividade (\%), respectivamente, porém, maior eficiência biológica $(106,60 \%)$ foi obtida com o substrato palha de arroz (Tabela 1).

Ao utilizar palha de trigo para cultivo de $P$. ostreatus linhagem 1314, Vogel; SALMONES (2000) descreveram resultados inferiores, pois citam eficiência biológica de $64,8 \%$ para a linhagem citada, sendo estes valores menores aos obtidos neste experimento, exceto quando comparados aos obtidos como bagaço de cana-de-açúcar. Os baixos valores obtidos com o substrato bagaço de cana-de-açúcar, durante este experimento, podem ser atribuídos à contaminação do substrato, que ocorreu nos primeiros dias do início da frutificação.

Apesar da contaminação por fungos competidores, o micélio do cogumelo apresentou alguns pontos de crescimento e colonização do substrato, com isso produzindo alguns poucos basidiomas, conforme se observa na Tabela 1, referindo-se especificamente à variável massa fresca. Esta contaminação pode ser associada ao fato do substrato bagaço de cana-de-açúcar apresentar maiores concentrações de açúcares, os quais podem ser de fácil assimilação e metabolismo para fungos competidores durante o cultivo de cogumelos.

Tabela 1 - Massa fresca (g), produtividade (\%) e eficiência biológica (\%) de Pleurotus sajor-caju (linhagem PSC96/03) cultiva em diferentes substratos pasteurizados.

\begin{tabular}{|c|c|c|c|c|}
\hline \multirow{2}{*}{ Variáveis } & \multirow{2}{*}{ Substratos } & \multicolumn{2}{|c|}{ Fluxos } & \multirow{2}{*}{ Total } \\
\hline & & $1^{\circ}$ & $2^{\circ}$ & \\
\hline \multirow{7}{*}{ 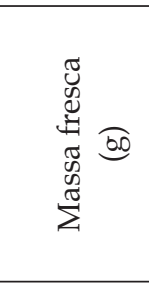 } & Capim-elefante & $178,20 \mathrm{bA}$ & $54,20 \mathrm{aB}$ & $232,40 a$ \\
\hline & Cana-de-açúcar & $31,60 \mathrm{gA}$ & $0,00 \mathrm{gB}$ & $31,60 \mathrm{~g}$ \\
\hline & Palha de arroz & $185,20 \mathrm{aA}$ & $28,00 \mathrm{fB}$ & $213,20 b$ \\
\hline & Capim-elefante + Cana-de-açúcar & $129,20 f A$ & $32,60 \mathrm{~dB}$ & $161,80 f$ \\
\hline & Capim-elefante + Palha de arroz & $139,40 \mathrm{dA}$ & $39,80 \mathrm{cB}$ & $179,20 \mathrm{~d}$ \\
\hline & Cana-de-açúcar + Palha de arroz & $138,60 \mathrm{eA}$ & $29,20 \mathrm{eB}$ & $167,80 \mathrm{e}$ \\
\hline & Capim-elefante + Cana-de-açúcar + Palha de arroz & $160,20 \mathrm{cA}$ & $46,00 \mathrm{bB}$ & $206,20 c$ \\
\hline \multirow{7}{*}{ 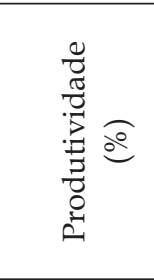 } & Capim-elefante & $17,82 \mathrm{bA}$ & $5,42 \mathrm{aB}$ & $23,24 a$ \\
\hline & Cana-de-açúcar & $3,16 \mathrm{gA}$ & $0,00 \mathrm{gB}$ & $3,16 \mathrm{~g}$ \\
\hline & Palha de arroz & $18,52 \mathrm{aA}$ & $2,80 \mathrm{fB}$ & $21,32 b$ \\
\hline & Capim-elefante + Cana-de-açúcar & $12,92 \mathrm{fA}$ & $3,26 \mathrm{~dB}$ & $16,18 \mathrm{f}$ \\
\hline & Capim-elefante + Palha de arroz & $13,94 \mathrm{dA}$ & $3,98 \mathrm{cB}$ & $17,92 d$ \\
\hline & Cana-de-açúcar + Palha de arroz & $13,86 \mathrm{eA}$ & $2,92 \mathrm{eB}$ & $16,78 \mathrm{e}$ \\
\hline & Capim-elefante + Cana-de-açúcar + Palha de arroz & $16,02 \mathrm{cA}$ & $4,60 \mathrm{bB}$ & $20,62 \mathrm{c}$ \\
\hline \multirow{7}{*}{ 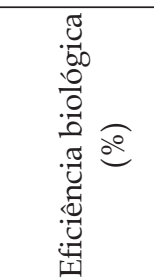 } & Capim-elefante & $71,28 \mathrm{cA}$ & $21,68 \mathrm{aB}$ & $92,96 c$ \\
\hline & Cana-de-açúcar & $15,80 \mathrm{gA}$ & $0,00 \mathrm{gB}$ & $15,80 \mathrm{~g}$ \\
\hline & Palha de arroz & $92,60 \mathrm{aA}$ & $14,00 \mathrm{fB}$ & $106,60 \mathrm{a}$ \\
\hline & Capim-elefante + Cana-de-açúcar & $57,42 \mathrm{fA}$ & $14,48 \mathrm{eB}$ & $71,90 \mathrm{f}$ \\
\hline & Capim-elefante + Palha de arroz & $61,96 \mathrm{eA}$ & $17,70 \mathrm{cB}$ & $79,64 \mathrm{e}$ \\
\hline & Cana-de-açúcar + Palha de arroz & $69,30 \mathrm{dA}$ & $14,60 \mathrm{~dB}$ & $83,90 \mathrm{~d}$ \\
\hline & Capim-elefante + Cana-de-açúcar + Palha de arroz & $74,18 \mathrm{bA}$ & $21,30 \mathrm{bB}$ & $95,48 b$ \\
\hline
\end{tabular}

Médias seguidas de mesma letra, minúscula nas colunas e maiúsculas nas linhas, não diferem entre si pelo teste de Tukey $(\alpha=0,05)$. Média de cinco repetições. Fluxo compreendendo 45 dias. 
Entretanto, em cultivo da linhagem IE-38 de $P$. ostreatus, em polpa de café, VeLÁzQUEZ-CEDEÑo et al. (2002) obtiveram $125 \%$ de eficiência biológica, resultados superiores quando comparados aos apresentados neste trabalho. SÁNCHES et al. (2002), cultivando a linhagem IE-8 em subprodutos da vitivinicultura, obtiveram eficiência biológica máxima de 78,73\%, valor este superior apenas aos obtidos com o bagaço de cana-de-açúcar e capim-elefante+bagaço decanade-açúcar durante este experimento.

BANIK; NANDI (2004), utilizando palha de arroz adicionada de esterco (1:1) para cultivo de $P$. sajor-caju, atingiram $120 \%$ de eficiência biológica. O cultivo de P. sajor-caju em bagaço de cana-de-açúcar pasteurizado foi avaliado por Moda et al. (2005), sendo que estes autores verificaram eficiência biológica de $13,86 \%$, valores estes inferiores aos obtidos durante este trabalho quando comparado ao mesmo tipo de substrato.

Os valores referentes à relação carbono/nitrogênio $(\mathrm{C} / \mathrm{N})$ podem ser visualizadas na Tabela 2, onde verifica-se maior relação $\mathrm{C} / \mathrm{N}$ para o substrato capim-elefante (162:1). O cultivo realizado com uma relação C/N 162:1 para Pleurotus sp. é considerado como alto, comparando-se com as relações descritas por EIRA; MinHONI (1997) os quais citam relação C:N entre 80-100:1 para o cultivo deste gênero de cogumelos. Contudo, este substrato foi o que apresentou maior massa fresca total de cogumelos produzidos, bem como maior produtividade quando comparado aos demais substratos. Já o substrato de menor relação C/N, ou seja, a palha de arroz (53:1) apresentou maior valor de eficiência biológica do cogumelo no substrato.

Ao se analisar a produtividade e eficiência biológica (Tabela 1) dos cogumelos produzidos durante este trabalho e a relação C:N inicial dos substrato (Tabela 2), pode-se verificar que a utilização de capim-elefante para o cultivo de $P$. sajor-caju (PSC96/03) não requer a suplementação com outros materiais de maiores teores de fontes nitrogenadas. Diferentemente de STURION (1994), o qual citou que, na fase de desenvolvimento dos basidiomas, a existência de uma relação $\mathrm{C} / \mathrm{N}$ baixa do substrato de cultivo é mais favorável. Já para ZANETTI; RANAL (1997), se por um lado o baixo teor de $\mathrm{N}$ diminui a produtividade, por outro os teores elevados desse nutriente também afetam negativamente a produção de basidiomas, onde existe uma concentração ideal de N para miceliação e produção, mas divergências no método e no cálculo dificultam a identificação deste valor.

Logo, de acordo com alguns autores, existe a necessidade de suplementação dos substratos utilizados no cultivo de cogumelos, objetivando incrementar os valores de produtividade e eficiência biológica. Assim, Vogel; SAlmones (2000) adi- cionaram farinha de soja na proporção de 5,5\% à massa seca do substrato composta por palha de trigo, no cultivo de três diferentes linhagens de Pleurotus spp. e observaram eficiência biológica de $58,8,64,8$ e $80,47 \%$, respectivamente, para as linhagens IE-227, 1314 e IE-226. Em outro experimento, estes mesmos autores utilizaram uma suplementação comercial, ao invés da farinha de soja, e observaram que a eficiência biológica da linhagem IE-226 aumentou para 99,3\%. Porém, em ambos os trabalhos acima citados, não são exemplificadas a relação $\mathrm{C} / \mathrm{N}$ resultante após a adição dos compostos nitrogenada.

A suplementação de casca de semente de girassol com $\mathrm{NH}_{4}^{+}$para a produção de P. ostreatus, em concentrações de 0 a 750 ppm, segundo CURVETTO et al. (2002), aumenta a produtividade desta espécie em até $50 \%$, pois promove o desenvolvimento miceliano através da adequação da relação $\mathrm{C} / \mathrm{N}$ do substrato utilizado. Uma das hipóteses discutidas por RoYSE (2002) é a adequação da relação C/N, o qual relata a suplementação dos substratos com diferentes nutrientes como um fator determinante para a produção de P. cornucopiae.

WANG et al. (2001), ao pesquisarem o cultivo de $P$. ostreatus, verificaram que a suplementação do substrato, à base de palha de cevada, com farelo de trigo até $45 \%$ proporcionou aumento na eficiência biológica do cogumelo. Trabalhando com palha de cereal, ao cultivarem $P$. sajor-caju em substrato à base de palha de milho pura e com suplementação de $10 \%$ de farelo de trigo, Dias et al. (2003) obtiveram 51\% de eficiência biológica com a palha pura e, com a suplementação, aumentou para $83 \%$. Já quando estes mesmos autores cultivaram em palha de feijão pura ou com a mesma suplementação não observaram diferenças, concluindo que não é necessário suplementar a palha de feijão para o cultivo desta espécie. Já BANIK; NANDI (2004) descreveram o aumento da eficiência biológica de P. sajor-caju cultivado em palha de arroz suplementada com esterco na proporção de 1:1, mas com aumento desta relação ocorreu uma diminuição da variável analisada. Por outro lado, Moda et al. (2005) citaram que para o cultivo deste mesmo cogumelo em bagaço de cana-de-açúcar suplementado com quirela de milho diminui a eficiência biológica.

Os resultados mostraram que a palha de arroz produz mais no primeiro fluxo e o capim-elefante no segundo, porém, no somatório dos dois fluxos para massa fresca e produtividade, destaca-se o cultivo de $P$. sajor-caju no capim-elefante e a eficiência biológica na palha de arroz, sendo ambos, separadamente, substratos viáveis para o cultivo de cogumelos. O bagaço de cana-de-açúcar foi o substrato menos indicado para o cultivo deste cogumelo por esta técnica. 
Tabela 2 - Relação carbono/nitrogênio dos substratos utilizados para o cultivo de Pleurotus sajor-caju (PSC96/03).

\begin{tabular}{lc}
\hline Substrato & Relação carbono/nitrogênio \\
\hline Capim-elefante & $162: 1$ \\
Bagaço de cana-de-açúcar & $143: 1$ \\
Palha de arroz & $53: 1$ \\
Capim-elefante + bagaço de cana-de-açúcar & $156: 1$ \\
Capim-elefante + palha de arroz & $102: 1$ \\
Bagaço de cana-de-açúcar + palha de arroz & $93: 1$ \\
Capim-elefante + bagaço de cana-de-açúcar + palha de arroz & $121: 1$ \\
\hline
\end{tabular}

Após a realização das análises bromatológicas (Tabela 3), pode-se verificar que os cogumelos produzidos no substrato composto por capim-elefante (50\%) e bagaço de cana-de-açúcar (50\%) foram os que apresentaram maiores teores de umidade $(91,41 \%)$, sendo também os responsáveis pelas maiores taxas de extrato etéreo $(5,65 \%)$, ou seja, maior quantidade de gordura, duas variáveis de baixo desejo alimentar quando se busca um alimento saudável. Logo, cogumelos produzidos no substrato composto por capimelefante, bagaço de cana-de-açúcare palha dearroz, na proporção de $33,33 \%$ cada componente, propiciaram maior quantidade de matéria seca $(14,37 \%)$. Os maiores teores de proteína bruta $(42,13 \%)$ e cinzas $(7,97 \%)$ foram obtidos a partir dos cogumelos produzidos no substrato composto por bagaço de cana-de-açúcar, sendo estes dois componentes de grandeimportância alimentar visto que apresentam, ou são formados, de muitos aminoácidos e minerais, respectivamente, necessários ao metabolismo celular humano. Já carboidratos $(58,66 \%)$ e fibra bruta $(31,33 \%)$ foram encontrados em maiores proporções nos substratos capim-elefante $(50 \%)$ mais palha de arroz $(50 \%)$ e no substrato palha de arroz, respectivamente.

A variação de substratos utilizados para o cultivo de Pleurotus sp. é amplamente verificada na literatura disponível, porém, poucos são os trabalhos relacionados à possíveis diferenças de coloração dos cogumelos produzidos. Durante este trabalho foram verificadas diferenças visuais na coloração dos cogumelos da espécie P. sajor-caju (PSC96/03), sendo que a coloração dos basidiomas variou de tonalidade cinza-clara a marrom-escuro. Pode-se verificar que os basidiomas, de P. sajor-caju (PSC96/03), produzidos nos substratos capim-elefante, bagaço de cana-deaçúcar + palha de arroz e capim-elefante + bagaço de cana-de-açúcar + palha de arroz, apresentaram coloração clara acinzentada. Porém, quando cultivados em bagaço de cana-de-açúcar e capim-elefante + palha de arroz, a cor dos basidiomas produzidos passou a se apresentar de forma marrom clara. Por fim, quando levados em consideração os substratos palha de arroz e capim-elefante+bagaço de canade-açúcar, os cogumelos passaram a ter aspecto marrom escuro, principalmente quando levado em consideração o substrato palha de arroz.

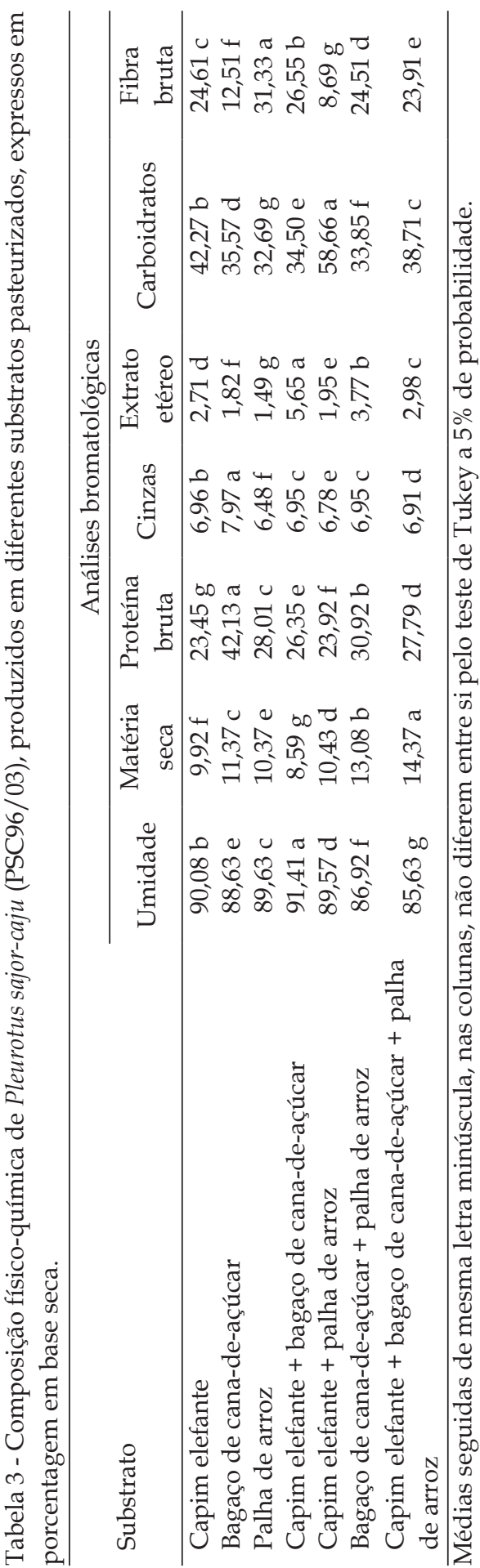




\section{CONCLUSÕES}

P. sajor-caju (PSC96/03) apresenta maiores valores de massa fresca, produtividade eficiência biológica em cultivo no substrato capim-elefante.

O bagaço de cana-de-açúcar utilizado de forma pura contamina-se rapidamente diminuindo o rendimento de P. sajor-caju (PSC96/03).

Os cogumelos produzidos no substrato capimelefante + bagaço de cana-de-açúcar apresentam elevados valores de extrato etéreo quando comparado aos demais.

A natureza dos substratos ou o tipo destes utilizados no cultivo alteram a coloração dos basidiomas.

\section{REFERÊNCIAS}

BANIK, S.; NANDI, R. Effect of supplementation of rice straw with biogas residual slurry manure on the yield, protein and mineral contents of oyster mushroom. Industrial Crops and Products, v.20, p.311-319, 2004

BERMUDÉZ, R.C.; GARCÍA, N.; GROSS, P.; SERRANO, M. Cultivation of Pleurotus on agricultural substrates in Cuba. Micologia Aplicada International, v.13, n.1, p.25-298, 2001

BERNARDI, E.; DONINI, L.P.; MINOTTO, E. NASCIMENTO, J.S. Cultivation of three Pleurotus (Jacq.: Fr.) P. Kumm. Species on pasteurized elephant grass (Pennisetum purpureum) substrate. International Journal of Medicinal Mushrooms, v.9, n.3/4, p.373-378, 2007.

CAPELARI, M. Atividade biodegradadora e cultivo de três espécies comestiveis de basidiomicetos: Pleurotus sp. e Agrocybe perfecta (Rick) Sing. 1996. 154f. Tese (Doutorado em Botânica) - Instituto de Biociências, Universidade de São Paulo, São Paulo, 1996.

CURVETTO, N.R.; FIGLAS, D.; DEVALIS, R.; DELMASTRO, S. Growth and productivity of different Pleurotus ostreatus strains on sunflower seed hulls supplemented with $\mathrm{N}-\mathrm{NH}_{4}{ }^{+}$and/or Mn(II). Bioresource Technology, v.84, p.171-176, 2002.

DIAS, E.S.; KOSHIKUMO, E.M.S.; SCHWAN, R.F ; SILVA, R. Cultivo do cogumelo Pleurotus sajor-caju em diferentes resíduos agrícolas. Ciência e Agrotecnologia, v.27, n.6, p.1363-1369, 2003.

DONINI, L.P.; BERNARDI, E.; MINOTTO, E.; NASCIMENTO, J.S. Desenvolvimento in vitro de Pleurotus sp. sob a influência de diferentes substratos e dextrose. Arquivos do Instituto Biológico, São Paulo, v.72, n.3, p.331338, 2005. Disponível em: < http:/ / www.biologico. sp.gov.br/docs/arq/V72_3/donini.PDF > . Acesso em: 19 out. 2009.
EIRA, A.F.; MINHONI, M.T.A. Manual teórico-prático do cultivo de cogumelos comestíveis. 2.ed. Botucatu: Fundação de Estudos e Pesquisas Agrícolas e Florestais, 1997. 115p.

INSTITUTO ADOLFO LUTZ. (São Paulo). Normas analíticas: métodos químicos e físicos para análise de alimentos. 3.ed. São Paulo: Instituto Adolfo Lutz, 1985. 533p.

MARINO, R.H. Produtividade de Pleurotus sajor-caju (Fr.) Sing. em função dos métodos de isolamento e produção de inoculantes. 1997. 134f. Dissertação (Mestrado em Agronomia) - Instituto de Química, Universidade Estadual Paulista, Araraquara, 1997.

MODA, E.M.; HORII, J.; SPOTO, M.H.F. Edible mushroom Pleurotus sajor-caju production on washed and supplemented sugarcane bagasse. Scientia Agricola, v.62, p.127-132, 2005.

REGINA, M. Cinética do crescimento miceliano de Lentinula edodes (Berk.) Pegler em bagaço de cana-de-açúcar e serragem de eucalipto. 2001. 87f. Dissertação (Mestrado em Agronomia) - Faculdade de Ciências Agronômicas, Universidade Estadual Paulista, Botucatu, 2001.

ROYSE, D.J. Influence of spawn rate and commercial delayed release nutrient levels on Pleurotus cornucopiae (oyster mushroom) yield, size, and time to production. Applied Microbiology and Biotechnology, v.58, p.527-531, 2002.

SÁNCHEZ, A.; YSUNZA, F.; BELTRÁN-GARCÍA, M.J.; ESQUEDA, M. Biodegradation of viticulture wastes by Pleurotus: a source of microbial and human food and its potential use in animal feeding. Journal of Agricultural and Food Chemistry, n.50, p.2537-2542, 2002.

SILVA, S.O.; COSTA,S.M.G.; CLEMENTE, E. Chemical composition of Pleurotus pulmonarius (Fr.) Quél., substrate and residue after cultivation. Brazilian Archives of Biology and Technology, v.45, n.4, p.531-535, 2002.

STURION, G.L. Utilização da folha de bananeira como substrato para o cultivo de cogumelos comestiveis (Pleurotus spp.). 1994. 56f. Dissertação (Mestrado em Ciência e Tecnologia de Alimentos) - Escola Superior de Agricultura Luiz de Queiroz, Piracicaba, 1994.

TEDESCO, M.J.; GIANELLO, C.; BISSANI, C.A.; BOHNEN, H.; VOLKWEISS, S.J. Análises de solo, plantas e outros materiais. 2.ed. Porto Alegre: Departamento de Solos, 1995. (Boletim Técnico, 5).

VELÁZQUEZ-CEDEÑO, M.A.; MATA, G.; SAVOIE, J. Waste-reducing cultivation of Pleurotus ostreatus and Pleurotus pulmonarius on coffee pulp: changes in the production of some lignocellulolytic enzymes. World Journal of Microbiology \& Biotechnology, v.18, p.201-207, 2002. 
VOGEL, F.; SALMONES, D. Análisis comparativo de la productividad de cepas de Pleurotus spp. cultivadas em uma planta comercial. Revista Iberoamericana de Micologia, v.17, p.138-141, 2000.

WANG, D.; SAKODA, A.; SUZUKI, M. Biological efficiency and nutritional value of Pleurotus ostreatus cultivated on spent beer grain. Bioresource Technology, v.78, p.293-300, 2001.

ZANETTI, A.L.; RANAL, M.A. Suplementação da cana-de-açúcar com guandu no cultivo de Pleurotus sp. 'Florida'. Pesquisa Agropecuária Brasileira, v.32, n.9, p.959-964, 1997.

ZONTA, E.P.; MACHADO, A.A. SANEST - Sistema de Análise Estatística para Microcomputadores. Registrado na Secretaria Especial de Informática sob nº 066060 - categoria A. Pelotas, RS: Universidade Federal de Pelotas, 1984.

Recebido em 19/1/10

Aceito em 25/4/11 